\title{
Beyond SARS-CoV-2: Lessons That African Governments Can Apply in Preparation for Possible Future Epidemics
}

\author{
Mary Aigbiremo Oboh ${ }^{1}$, Semeeh Akinwale Omoleke ${ }^{2}$, Christian Eseigbe Imafidon ${ }^{3}$, Olumide Ajibola ${ }^{1,4}$, \\ Eniyou Cheryll Oriero', Alfred Amambua-Ngwa' ${ }^{1}$ \\ ${ }^{1}$ Medical Research Council Unit, The Gambia at London School of Hygiene and Tropical Medicine, Banjul, Gambia; ${ }^{2}$ Immunization, Vaccines and \\ Emergencies Unit, World Health Organization, Kebbi State Field Office, Birnin Kebbi, Nigeria; ${ }^{3}$ Renal Research Laboratory, Department of \\ Physiology, Bowen University College of Health Sciences, Iwo, Nigeria; ${ }^{4}$ Department of Biology, First Technical University, Ibadan, Nigeria
}

Severe acute respiratory syndrome coronavirus 2 (SARS-CoV-2) has placed unprecedented pressure on healthcare systems, even in advanced economies. While the number of cases of SARS-CoV-2 in Africa compared to other continents has so far been low, there are concerns about under-reporting, inadequate diagnostic tools, and insufficient treatment facilities. Moreover, proactiveness on the part of African governments has been under scrutiny. For instance, issues have emerged regarding the responsiveness of African countries in closing international borders to limit trans-continental transmission of the virus. Overdependence on imported products and outsourced services could have contributed to African governments' hesitation to shut down international air and seaports. In this era of emerging and re-emerging pathogens, we recommend that African nations should consider self-sufficiency in the health sector as an urgent priority, as this will not be the last outbreak to occur. In addition to the Regional Disease Surveillance Systems Enhancement fund (US\$600 million) provided by the World Bank for strengthening health systems and disease surveillance, each country should further establish an epidemic emergency fund for epidemic preparedness and response. We also recommend that epidemic surveillance units should create a secure database of previous and ongoing pandemics in terms of aetiology, spread, and treatment, as well as financial management records. Strategic collection and analysis of data should also be a central focus of these units to facilitate studies of disease trends and to estimate the scale of requirements in preparation and response to any future pandemic or epidemic.

Key words: SARS-CoV-2, African government, Trans-continental transmission, Travel restrictions, Medical supplies

Severe acute respiratory syndrome coronavirus 2 (SARS-CoV2), which was initially detected in Wuhan, China in December 2019, has gradually snowballed into a worldwide pandemic [1]. It has placed unprecedented pressure on healthcare systems,

Received: June 9, 2020 Accepted: August 18, 2020

Corresponding author: Mary Aigbiremo Oboh, PhD Medical Research Council Unit, The Gambia at London School of Hygiene and Tropical Medicine, Banjul, P.O. Box 273, Gambia

E-mail: moboh@mrc.gm

This is an Open Access article distributed under the terms of the Creative Commons Attribution Non-Commercial License (https://creativecommons.org/licenses/by$\mathrm{nc} / 4.0 /$ ) which permits unrestricted non-commercial use, distribution, and reproduction in any medium, provided the original work is properly cited. even in advanced economies [1]. As of April 20, 2020, there were over 2.2 million confirmed cases globally and 152551 recorded deaths [1]. Although the numbers of cases and deaths reported in Africa remain comparatively low [2], this might be an underrepresentation of the disease burden due to the challenges of insufficient diagnostic testing kits and centres relative to the teeming high population of the continent. These inadequacies are major causes of concern for disease control efforts, given the potential for gradual but steady geometric inter-community and intra-community spread because the virus has a high reproductive number and a short serial interval [3].

Given the various epidemic events that have previously oc- 
curred in Africa, from Ebola virus disease (EVD) [4] to yellow fever, cholera, measles and Lassa fever [5], it would almost be safe to assume that African governments have prepared proactive measures against possible future epidemics. However, such proactive measures in Africa towards pandemic situations still seem to be far-fetched, as demonstrated by the approach towards the novel SARS-CoV-2 pandemic. Considering the high virulence of the pathogen and the rapid spread of the disease, there was a significant time lapse between the first confirmed case outside of China (Thailand, on January 13, 2020) and confirmation of the first SARS-CoV-2 case in Africa (specifically, in Egypt on February 14, 2020) compared to other continents [6]. The question then arises that, beyond the current containment efforts by various African countries, could they have done better to prevent the spread of this viral infection into and within the continent based on previous experiences with other emerging and re-emerging pathogens?

With the great risk of trans-continental transmission of pathogenic agents due to the high emigrational tendency of Africans to Western countries and vice versa (for greener pastures and/ or tourism), and dependency on imported products into the continent from countries in the global north, African leaders should have been more proactive in closing and/or reducing travel into the continent. A measure could have been applied to restrict travel even from countries with fewer than 100 confirmed SARS-CoV-2 cases given that the virus is highly transmissible, with a high reproductive number [3]. For example, Nigeria's travel ban was implemented on March 18, 2020 (3 weeks after the first imported case) for 13 countries with more than 1000 cases at that time, despite convincing evidence regarding potential importation from other countries not listed, while a total airport ban came a week later (March 23, 2020) [7]. Some proactive countries such as Djibouti suspended all international flights before recording any cases of SARS-CoV-2 in the country. The authors are aware of the International Health Regulations, which frown at undue impositions of travel and trade restrictions due to a public health emergency of international concern. However, in the context of overwhelming evidence of an absent or inadequate national capacity to respond or cope with the epidemic, it is inevitable for countries to promptly wield international and local travel restrictions to slow down and reduce the peak of the epidemic.

African countries, with their heavy reliance on their counterparts in the global north for medical supplies, should have purchased medical consumables, such as testing kits and per- sonal protective equipment, and should have initiated training of personnel and surveillance officers who will be needed in the event of an epidemic. It is worrisome, however, to observe different ministries of health from African countries scavenging for these supplies when they are already burdened with hundreds of active cases. Apparently, borders and air spaces were left open, yet with little or no preparations made for the potential cases that were allowed into the countries.

Generally, the continent of Africa suffers from deficiencies in human capacity and infrastructure, especially in medical and health research [8]. Hence, without the availability of the necessary consumables, trained laboratory scientists, clinicians, nurses, and other health workers for effective case management and systematic contact tracing, there will still be a huge gap in the management of coronavirus disease 2019 (COVID-19) pandemic in Africa, with potentially disastrous consequences. Evidence suggests that many African countries had a relatively weak epidemic preparedness and response capacity before the current outbreak [9]. These weaknesses have improved modestly, but not sufficiently to combat the COVID-19 pandemic.

Despite the challenges mentioned above and the aftermath of the 2014 West African Ebola crisis, the World Bank supported the launching of the Regional Disease Surveillance Systems Enhancement (REDISSE) with US\$600 million to strengthen the health systems and disease surveillance in 16 West and Central African countries. Similarly, funds have been provided to support the African Centers for Disease Prevention and Control to build human capacity, provide guidelines, and coordinate epidemic prevention and response activities across the African continent. Furthermore, other lessons learnt and builtup from the recent EVD outbreak prompted the implementation of improved airport surveillance, temperature screening at points of entry, and training and scaling up of molecular diagnostic capacity for SARS-CoV-2 [10]. A few countries, such as Nigeria, South Africa, Algeria, Ghana, and Egypt, initiated some of these measures somewhat earlier, but were not decisive about the implementation of travel restrictions or bans, thereby allowing the importation of SARS-CoV-2 virus into Africa.

Some key lessons from the current outbreak of SARS-CoV-2 include the dire need to improve hospital facilities (e.g., intensive care unit upgrading and expansion through the procurement of ventilators and other life-saving equipment, upgrading emergency medical facilities, and improved diagnostic capacity), retention of highly skilled human resources, epidemic 
preparedness, sustained surveillance, and baseline health demographic data for chronic infectious and non-communicable diseases that could serve as potential risk factors for aggravated outcomes of new and emerging diseases. African leaders cannot afford to be complacent in responding to such issues given their previous encounters with EVD, and now SARS-CoV-2. These experiences should serve as a wake-up call for African countries to prepare for possible future outbreaks.

In conclusion, Africa and the world at large will never remain the same after the COVID-19 pandemic. Therefore, the heads of states on the African continent should adopt preventive and precautionary measures rather than reactionary measures.

In addition to the REDISSE fund (US $\$ 600$ million) created by the World Bank for strengthening health systems and disease surveillance, each country should further map out an epidemic emergency fund that will be used to address situations such as this in the future. Further, we recommend that epidemic surveillance units, under the Ministry of Health, should be strengthened in all African countries. These units should be given the responsibility to create a secure database of previous and ongoing pandemics in terms of aetiology, spread, and treatment, as well as financial management records. Strategic collection and analysis of data should also be a central focus of these unit to facilitate the analysis of disease trends and to estimate the scale of all necessary resources in preparation and response to any future pandemic or epidemic.

\section{Ethics Statement}

This paper is a perspective, so it did not need ethical approval.

\section{CONFLICT OF INTEREST}

The authors have no conflicts of interest associated with the material presented in this paper.

\section{FUNDING}

None.

\section{ACKNOWLEDGEMENTS}

None.

\section{AUTHOR CONTRIBUTIONS}

Conceptualization: MAO. Funding acquisition: None. Writing original draft: MAO, SAO, CEI, OA. Writing - review \& editing: $\mathrm{MAO}, \mathrm{SAO}, \mathrm{CEI}, \mathrm{OA}, \mathrm{ECO}, \mathrm{AAN}$.

\section{ORCID}

Mary Aigbiremo Oboh https://orcid.org/0000-0001-57208425

Semeeh Akinwale Omoleke https://orcid.org/0000-00030538-9126

Christian Eseigbe Imafidon https://orcid.org/0000-00023806-964X

Olumide Ajibola https://orcid.org/0000-0001-6860-3607

Eniyou Cheryll Oriero https://orcid.org/0000-0002-79116457

Alfred Amambua-Ngwa https://orcid.org/0000-0003-44783601

\section{REFERENCES}

1. Livingston E, Bucher K, Rekito A. Coronavirus disease 2019 and influenza 2019-2020. JAMA 2020;323(12):1122.

2. Africa Centre for Disease Control and Prevention. COVID-19 scientific and public health policy update - (March 24, 2020) [cited 2020 Jun 16]. Available from: https://africacdc.org/ download/covid-19-scientific-and-public-health-policy-update-march-24-2020/.

3. Xie $\mathbf{M}$, Chen Q. Insight into 2019 novel coronavirus - an updated interim review and lessons from SARS-CoV and MERS-CoV. Int J Infect Dis 2020;94:119-124.

4. Joshi RM. Ebola virus disease (EVD): an unprecedented major outbreak in West Africa. Clin Microbiol 2014;3(6):e119.

5. Mboussou F, Ndumbi P, Ngom R, Kamassali Z, Ogundiran O, Van Beek J, et al. Infectious disease outbreaks in the African region: overview of events reported to the World Health Organization in 2018. Epidemiol Infect 2019;147:e299.

6. World Health Organisation. Coronavirus disease 2019 (COVID19) situation report - 26; 2020 Feb 15 [cited 2020 Jun 16]. Available from: https://www.who.int/docs/default-source/coronaviruse/situation-reports/20200215-sitrep-26-covid-19.pdf? sfvrsn $=\mathrm{a} 4 \mathrm{cc} 6787$ 2.

7. Nigerian Civil Aviation Authority. Update on clarification of flight restriction into Nigeria due to COVID-19 pandemic; 2020 
Mar 21 [cited 2020 Jun 16]. Available from: https://ncaa.gov. ng/media-center/news/update-on-clarification-of-flight-restriction-into-nigeria-due-to-covid-19-pandemic/.

8. Gilbert M, Pullano G, Pinotti F, Valdano E, Poletto C, Boëlle PY, et al. Preparedness and vulnerability of African countries against importations of COVID-19: a modelling study. Lancet 2020; 395(10227):871-877.

9 Omoleke SA, Ajibola O, Ajiboye JO, Raji RO. Quagmire of epi- demic disease outbreaks reporting in Nigeria. BMJ Glob Health 2018;3(1):e000659.

10 World Health Organization Regional Office for Africa. WHO ramps up preparedness for novel coronavirus in the African region; 2020 Jan 31 [cited 2020 Jun 16]. Available from: https:// www.afro.who.int/news/who-ramps-preparedness-novelcoronavirus-african-region. 